\section{Let's stop fooling ourselves. In RA, only ACR/EULAR criteria define remission and equate with absence of disease!}

I read with interest the report on the C-EARLY study. ${ }^{1}$ The study has been performed well, and the data support the conclusions. I do, however, take issue with the definition of the chosen endpoint of 'sustained remission', that is, a DAS28<2.6 at weeks 40 and 52. First, a period of 12 weeks is arbitrary and, in my view, rather short for a claim of 'sustained remission', but this is not my major worry. The new American College of Rheumatology/European League Against Rheumatism (ACR/ EULAR) remission criteria for rheumatoid arthritis (RA) were published in the spring of $2011,{ }^{2}$ with Paul Emery, Dan Furst and Desiree van der Heijde as coauthors, all of whom are also coauthors on this manuscript. A check at the Trial Register shows the trial was registered on 19 January 2012, at which time, enrolment also started. This by itself is a curious finding, as most ethical review boards require a registration in a trials register before a trial can be approved, and recruitment usually does not start within days of approval.

However, the key point is that the designers of the study were aware of the ACR/EULAR remission criteria during protocol design, so that there was no scientific reason NOT to use the new criteria to define the primary endpoint. There was, of course, a pragmatic reason: the new criteria try to define true remission, or absence of disease, which is difficult to achieve, whereas DAS2 $8<2.6$ is easier to achieve, but does NOT represent absence of disease, as has been shown ad nauseam in many studies, including studies performed by some of the authors on this recent trial. In the C-EARLY trial, the prevalence of real sustained remission (using the same period of 12 weeks) undoubtedly was lower than that reported as primary endpoint; but given the overall prevalence of ACR/EULAR remission reported as secondary outcome, most likely, the contrast between the treatment groups would have been maintained with a properly defined endpoint. So, in my view, a very nice study was unnecessarily diminished by this unscientific definition of the primary endpoint. And if the authors preferred a less stringent endpoint, they could have termed it differently (eg, 'sustained minimal disease activity'), or, as a last resort, reviewers or the Editor could have forced them to do so.

It is time the scientific community, including peer reviewers and Editors of major rheumatology journals, and especially the Editors of the EULAR and ACR journals, put a stop to the use of the word 'remission' in RA study publications when this refers to definitions other than the agreed ACR/EULAR criteria.

\section{Maarten Boers}

Correspondence to Dr Maarten Boers Department of Epidemiology \& Biostatistics, Amsterdam Rheumatology and Immunology Center, PO Box 7057, Amsterdam 1007 $M B$, The Netherlands; eb<at>vumc.nl

Competing interests None declared.

Provenance and peer review Not commissioned; internally peer reviewed.

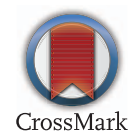

To cite Boers M. Ann Rheum Dis 2016;75:e68.

Received 15 June 2016

Accepted 19 June 2016

Published Online First 7 July 2016

\section{(5) Linked}

http://dx.doi.org/10.1136/annrheumdis-2016-210083

Ann Rheum Dis 2016;75:e68. doi:10.1136/annrheumdis-2016-210063

\section{REFERENCES}

1 Emery P, Bingham CO III, Burmester GR, et al. Certolizumab pegol in combination with dose-optimised methotrexate in DMARD-naive patients with early, active rheumatoid arthritis with poor prognostic factors: 1-year results from C-EARLY, a randomised, double-blind, placebo-controlled phase III study. Ann Rheum Dis 2016:75:e69

2 Felson DT, Smolen JS, Wells G, et al. American College of Rheumatology/European League against Rheumatism provisional definition of remission in rheumatoid arthritis for clinical trials. Ann Rheum Dis 2011;70:404-13. 